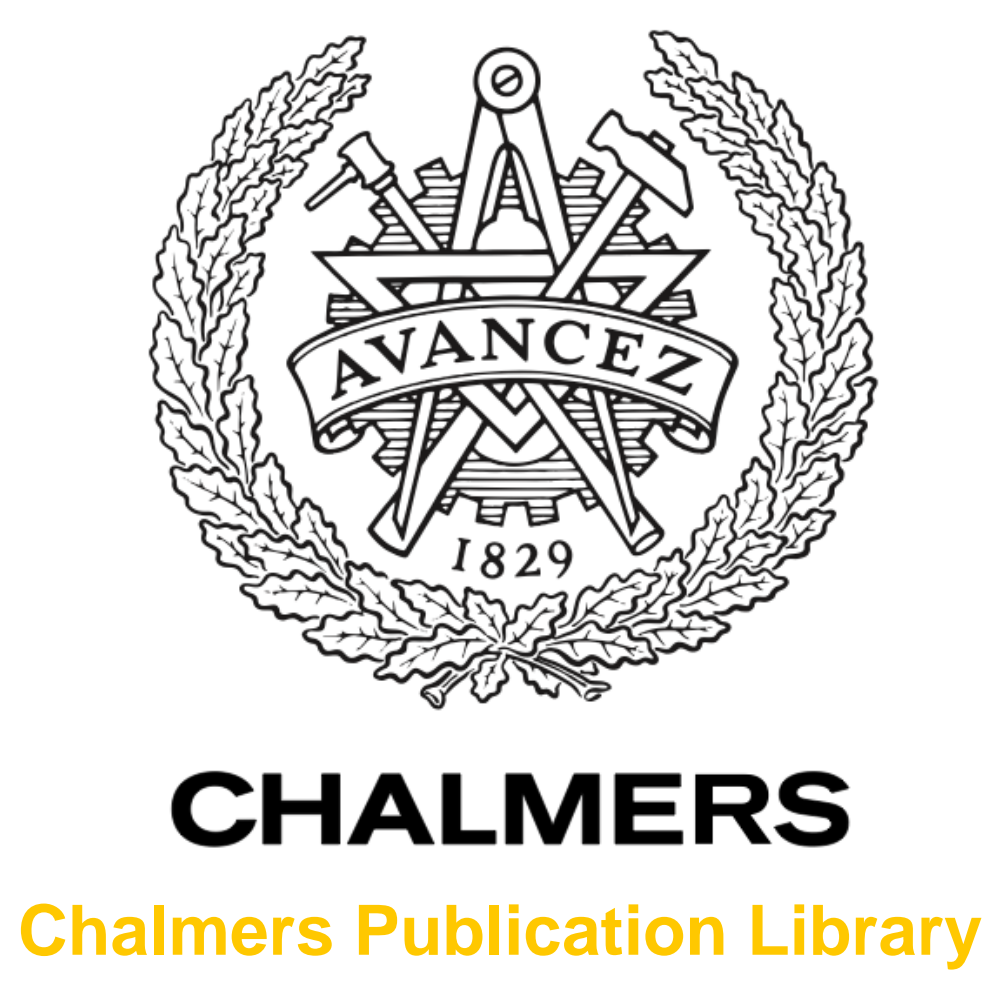

\title{
A groove gap Waveguide Iris Filter for V-band Application
}

This document has been downloaded from Chalmers Publication Library (CPL). It is the author's version of a work that was accepted for publication in:

23rd Iranian Conference on Electrical Engineering (ICEE), 2015

Citation for the published paper:

Rezaee, M. ; Zaman, A. ; Kildal, P. (2015) "A groove gap Waveguide Iris Filter for V-band Application". 23rd Iranian Conference on Electrical Engineering (ICEE), 2015 pp. 462-465.

http://dx.doi.org/10.1109/IranianCEE.2015.714625

Down「oaded from: http://publications.lib.chalmers.se/publication/227721

Notice: Changes introduced as a result of publishing processes such as copy-editing and formatting may not be reflected in this document. For a definitive version of this work, please refer to the published source. Please note that access to the published version might require a subscription.

Chalmers Publication Library (CPL) offers the possibility of retrieving research publications produced at Chalmers University of Technology. It covers all types of publications: articles, dissertations, licentiate theses, masters theses, conference papers, reports etc. Since 2006 it is the official tool for Chalmers official publication statistics. To ensure that Chalmers research results are disseminated as widely as possible, an Open Access Policy has been adopted.

The CPL service is administrated and maintained by Chalmers Library. 


\section{A Groove Gap Waveguide Iris Filter for V-Band Application}

\author{
Morteza Rezaee \\ Department of Electrical Engineering \\ Ferdowsi University of Mashhad \\ Mashhad, Iran \\ morteza.rezaee@mail.um.ac.ir
}

\author{
Ashraf Uz Zaman, Per-Simon Kildal \\ Department of Signals and System \\ Chalmers University of Technology \\ SE-41296, Gothenburg, Sweden \\ zaman@chalmers.se,per-simon.kildal@chalmer.se
}

\begin{abstract}
This work presents a V-band iris filter, based on recently introduced groove gap waveguide technology. In this technology, it doesn't need to have electrical contact between two constituting metallic surfaces, as it is needed in conventional hollow waveguides. Therefore, it is cheaper to manufacture gap waveguide components, in particular in millimeter wave frequency range. In this work, square shape groove gap waveguide cavities are used as filter resonators. To realize the input/output coupling and also inter cavity coupling, two larger pins are used to act as an iris. A fifth order bandpass Chebyshev filter is designed with $1 \mathrm{GHz}$ bandwidth at $59.5 \mathrm{GHz}$ center frequency and a prototype is manufactured to validate the simulation results. Design process, simulated results, and measured results are presented here.
\end{abstract}

Keywords-coupled resonator filter; gap waveguide; groove gap waveguide; microwave filter

\section{INTRODUCTION}

Microwave filter is an important part of many wireless communication systems and are commonly realized in hollow waveguide structure for frequencies between 3 and $30 \mathrm{GHz}$, due to low insertion loss and high power handling capability [1]. The hollow rectangular waveguide filters usually are manufactured in two separate metallic parts that are connected together by screws. At frequencies above $30 \mathrm{GHz}$, the electrical contact between two metal split bocks becomes more important. Poor electrical contact reduces the quality factor of the hollow waveguide resonators and also causes the Passive Intermodulation (PIM), due to leakage and finite conductivity [2]. Obtaining good electrical contact between two metallic parts at millimeter wave frequency range is very difficult, due to the need of high quality surface roughness and protection against corrosion of the metal contact area, and hence, the manufacturing cost of conventional waveguide filter is increased. Moreover, integrating the rectangular waveguide by other active components mounted on the printed circuit board can be difficult.

To overcome these limitations of hollow waveguides, a new technology, called gap waveguide technology, has been introduced recently [3]. The gap waveguide structure consists of a Perfect Electric Conductor (PEC) surface and a Perfect Magnetic Conductor (PMC) surface where propagation of parallel-plate modes is forbidden while distance between the two surfaces is smaller than $\lambda / 4$. As shown in Fig. 1(a), by incorporating a hard surface over the PMC layer, EM field propagation between these two parallel surfaces is made possible without any leakage to transversal directions, as a local quasi-TEM wave [4]. The PMC surface can be realized by a periodic structure as an Artificial Magnetic Conductor (AMC), for instance by periodic metallic pins [5] and periodic mushroom type vias in a substrate [6]. Up to now, four types of gap waveguide structure have been proposed with different hard surface, including groove, ridge, microstrip [7], and microstrip-ridge gap waveguide [6]. The main advantage of gap waveguide is that it doesn't need any metal contact between two separate metal blocks, also having almost the same loss as a hollow waveguide. Moreover, the active RF circuits can be integrated in this structure without extra resonances due to packaging properties of gap waveguide [8]. Because of being open structure, the air cooling can be done easily and hence, high power handling capability is improved.
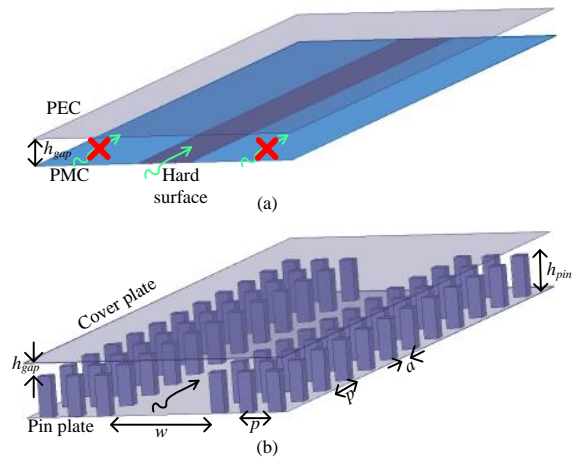

Fig. 1. (a) General structure of gap waveguide technology.

(b) Groove gap waveguide structure.

So far, gap waveguide passive components such as slot array antennas and band-pass filters have been designed mainly at $\mathrm{Ku}$ band and $\mathrm{Ka}$ band as a proof of concept [9-10]. However, recently millimeter wave gap waveguide structures have been published as a transmission line [6] and as an antenna [11]. Among all the gap waveguide geometries, the groove gap waveguide structure has $\mathrm{TE}_{10}$-type mode propagation, like in rectangular waveguide [12], and has the highest quality factor among the different types of gap waveguides [13]. In this paper, a novel iris filter based on groove gap waveguide structure is presented. To create irises, two pins are selected with different size with respect to the pin grid. Two transitions from groove gap waveguide to WR-15 
waveguides are also designed. The design procedure, simulation results and measured results are presented in the following sections.
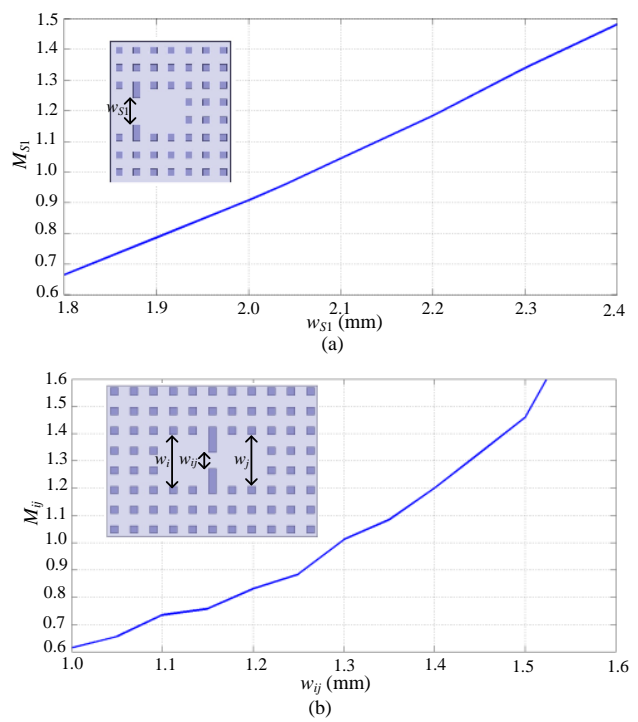

Fig. 3. (a) Input coupling coefficient versus iris width $w_{s 1}$ and (b) inter cavity coupling coefficient versus iris width $w_{i j}$. $\left(h_{p i n}=1.25 \mathrm{~mm}, h_{g a p}=\right.$ $0.25 \mathrm{~mm}, p=1.3 \mathrm{~mm}, a=0.5 \mathrm{~mm}, w_{i}=w_{j}=3.4 \mathrm{~mm}$ )

\section{Groove GAP WAVEGUIDE FILTER DESIGN}

\section{A. Groove Gap Waveguide}

Fig. 1 (b) shows the groove gap waveguide consisting of two PEC parallel plates, called cover plate and pin plate, and a bed of periodic metallic pins on the pin plate. To realize an AMC over the pin plate, the height of pins, $h_{p i n}$, should be $\lambda / 4$ and pins period, $p$, should be less than $\lambda / 2$. To stop the propagation of parallel plate modes between pins and cover plate, air gap, $h_{\text {gap }}$, should be smaller than $\lambda / 4$.

\section{B. Transition of Groove Gap Waveguide to WR-15}

Fig. 2 (a) shows the designed transition from groove gap waveguide to WR-15 via an aperture of width $w_{a p}$ in the pin plate. The width of aperture and also its position with respect to the back groove gap waveguide walls are selected to obtain a good matching. The frequency response of the optimized transition is shown in Fig. 2 (b). The simulated return loss and insertion loss by considering silver metal is better than $20 \mathrm{~dB}$ and $0.1 \mathrm{~dB}$, respectively, over the fractional bandwidth of $7.5 \%$.

\section{Filter Design}

Generally, an Nth-order cross-coupled resonator filter can be modeled and synthesized by a coupling matrix. The coupling coefficients for a synchronously tuned fifth-order Chebyshev filter with return loss better than $20 \mathrm{~dB}$ are

$$
\begin{aligned}
& M_{S 1}=M_{L 5}=1.0136, \quad M_{12}=M_{45}=0.8653 \\
& M_{23}=M_{34}=0.6357
\end{aligned}
$$

Square shape groove gap waveguide cavities are used as filter resonators with $\mathrm{TE}_{101}$-like resonant mode. The input (output) coupling to the first (last) resonator, i.e. $M_{S 1}\left(M_{L 5}\right)$, can be realized as shown in the inset of Fig. 3(a) by two longer pins than the other pins. Input coupling coefficient versus input iris width, $w_{S 1}$, is depicted in Fig. 3(a). The inter-cavity coupling between $i$ th and $j$ th resonators, $M_{i j}$, is also realized using the structure shown in the inset of Fig. 3(b). $M_{i j}$ coefficient is also controlled by iris width, $w_{i j}$, as depicted in Fig. 4(b). To control the center frequency of $i$ th square groove gap waveguide cavity, slightly, one side length of cavity, $w_{i}$, is changed by dimensions of surrounding pins.
3D view

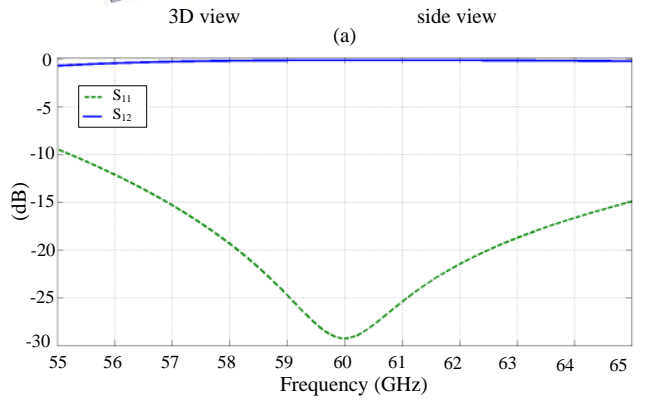

(b)

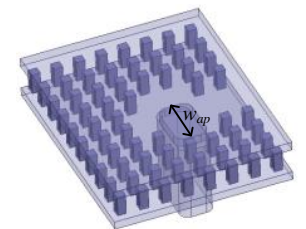

Fig. 2. (a) Transition of groove gap waveguide to WR-15 and (b) its frequency response $\left(w_{a p}=2.9 \mathrm{~mm}\right)$.

The proposed groove gap waveguide iris filter is depicted in Fig. 4 (a). To have a more cost effective manufacture, the grid of pins is chosen regularly and also, all the pins have equal height. Using the design graphs depicted in Fig. 3 and coupling coefficients, the filter is designed. The synthesized frequency response of filter obtained from coupling matrix and the simulated frequency response obtained using HFSS are shown in Fig. 4(b) and a good agreement can be seen. The simulated fractional bandwidth at $59.5 \mathrm{GHz}$ center frequency is $1.83 \%$ with return loss better than $14 \mathrm{~dB}$ and the minimum insertion loss is $0.8 \mathrm{~dB}$.

\section{RESUlTS AND DISCUSSION}

Photograph of the fabricated groove gap waveguide filter is illustrated in Fig. 5(a). Sawing and milling techniques are used to manufacture the filter with brass as base metal and then silver plating of $10 \mu \mathrm{m}$ thickness is applied. A comparison between the simulated and measured frequency response is depicted in Fig. 5(b). The measured fractional bandwidth at $59.7 \mathrm{GHz}$ center frequency is $1.34 \%$ with return loss better than $9 \mathrm{~dB}$ and the minimum insertion loss is $1.7 \mathrm{~dB}$. As is seen in Fig. 5(b), the center frequency of filter is shifted to higher frequency and the bandwidth is decreased. From the simulation of the filter with added silver plating thickness on pins and also measuring of the manufactured filter dimensions 


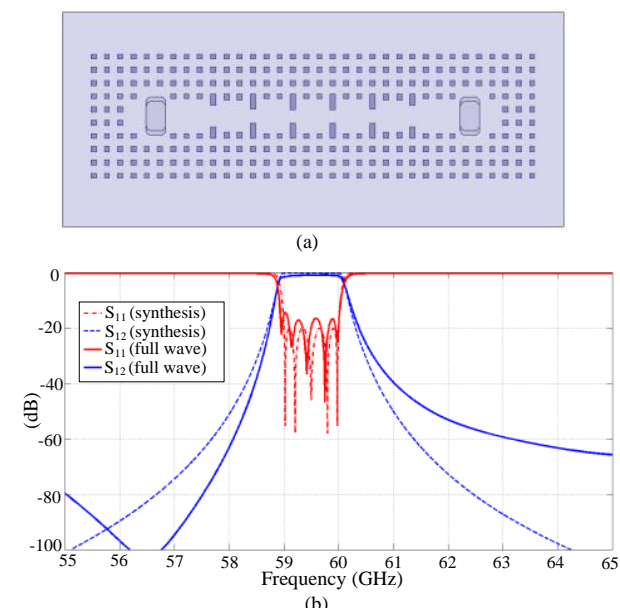

(b)

Fig. 4. (a) Top view of the proposed fifth-order groove gap waveguide filter. (b) The calculated and simulated frequency response. $\left(w_{S 1}=2.07 \mathrm{~mm}, w_{1}=3.15 \mathrm{~mm}, w_{12}=1.41 \mathrm{~mm}\right.$, $\left.w_{2}=3.44 \mathrm{~mm}, w_{23}=1.32 \mathrm{~mm}, w_{3}=3.46 \mathrm{~mm}\right)$.

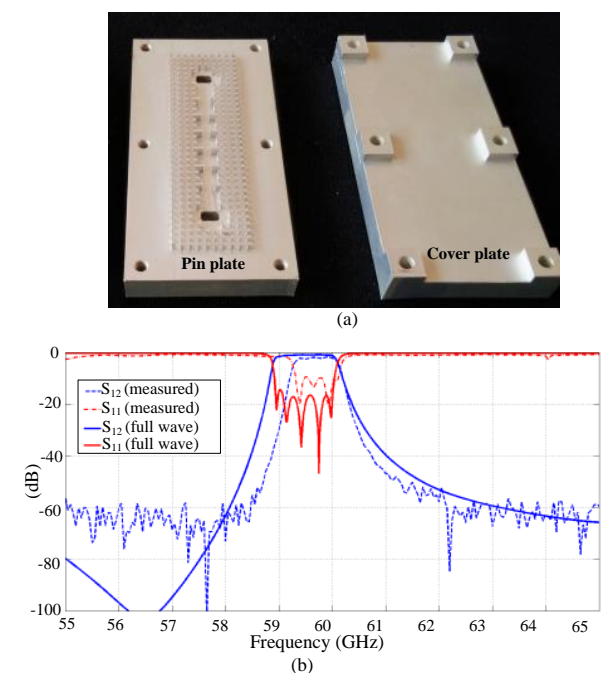

Fig. 5. (a) Photograph of the prototype groove gap waveguide filter with holes for assembling and (b) its measured frequency response.

by electronic microscope, it can be concluded that this frequency response degradation is because of silver plating and also fabrication tolerance of $\pm 25 \mu \mathrm{m}$. Indeed, silver plating decreases the cavity size and also, decreases the opening of the coupling irises and increases the iris thickness and hence, the center frequency is shifted to higher frequency and the bandwidth is decreases.

\section{CONCLUTION}

A V-band iris groove gap waveguide filter has been designed, fabricated, and measured. Using the gap waveguide technology, conducting joint between two metal parts is not required. $\mathrm{TE}_{101}$-like mode of the square shaped groove gap cavity is used as filter resonators that are coupled by irises. Transition via cover plate from groove gap waveguide to WR15 is designed. A prototype filter is manufactured and measured.

\section{Acknowledgment}

This work has been financially supported by the Swedish Governmental Agency for Innovation Systems VINNOVA via a project within the VINN Excellence center Chase and the European Research Council (ERC) via an advanced investigator grant ERC-2012-ADG_20120216. Also, the authors would like to thank Dr. Ali Khaleghi of KNTU, Tehran, Iran for manufacturing the filter.

\section{References}

[1] G. L. Matthaei, L. Young, and E. M. T. Jones, Microwave Filters, Impedance Matching Networks and Coupling Structures. Norwood, MA: Artech House, 1964.

[2] C. Vicente and H. L. Hartnagel, "Passive-intermodulation analysis between rough rectangular waveguide flanges," Microwave Theory and Techniques, IEEE Transactions on, vol. 53, no. 8, pp. 2515-2525, 2005.

[3] P.-S. Kildal, E. Alfonso, A. Valero-Nogueira, and E. Rajo-Iglesias, "Local metamaterial-based waveguides in gaps between parallel metal plates," IEEE Antennas Wireless Propag. Lett., vol. 8, pp. 84-87, 2009.

[4] A. Valero-Nogueira, E. Alfonso, J. I. Herranz, P.-S. Kildal, "Experimental demonstration of local quasi-TEM gap modes in singlehard- wall waveguides", IEEE Microwave and Wireless Comp. Lett., vol. 19, No. 9, pp. 536-538, Sept. 2009.

[5] E. Rajo-Iglesias and P.-S. Kildal, "Numerical studies of bandwidth of parallel plate cut-off realized by bed of nails, corrugations and mushroom- type EBG for use in gap waveguides," IET Microw. Antennas Propag., vol. 5, no. 3, pp. 282-289, Mar. 2011

[6] H. Raza, J. Yang, P.-S. Kildal, and E. Alfonso, "Microstrip-ridge gap waveguide - study of losses, bends, and transition to WR-15," IEEE Transactions on Microwave Theory and Techniques, vol. 62, no. 9, pp. 1943 - 1952, 2014.

[7] P. S. Kildal, "Three metamaterial-based gap waveguides between parallel metal plates for $\mathrm{mm} / \mathrm{submm}$ waves," in 3rd European Conference on Antennas and Propagation, EuCAP 2009, pp. 28-32.

[8] A.U. Zaman, T. Vukusic, M. Alexanderson, P.-S. Kildal, "Gap waveguide PMC packaging for improved isolation of circuit components in high frequency microwave modules", IEEE Trans. On Compon., Packag. Manuf. Technol., Vol. 4, Issue 1, p. 16 - 25, 2014.

[9] A. U. Zaman and P. S. Kildal, "Wide-Band Slot Antenna Arrays With Single-Layer Corporate-Feed Network in Ridge Gap Waveguide Technology," Antennas and Propagation, IEEE Transactions on, vol. 62, pp. 2992-3001, 2014.

[10] E. Alfonso Alos, A. U. Zaman, and Per-Simon Kildal, "Ka-band Gap Waveguide Coupled-Resonator Filter for Radio Link Diplexer Application", IEEE Trans. on Comp., Packag. Manuf. Technol., vol. 3, No. 5, pp. 870-879, May 2013.

[11] S. A. Razavi, P.-S. Kildal, L. Xiang and E. Alfonso, "2×2-slot Element for $60 \mathrm{GHz}$ Planar Array Antenna Realized on Two Doubled-sided PCBs Using SIW Cavity and EBG-type Soft Surface fed by Microstrip-Ridge Gap Waveguide", IEEE Trans. on Antennas and Propag., vol. 62, no. 9, pp. 4564 - 4573, 2014.

[12] H. Raza, J. Yang, P.-S. Kildal, and E. Alfonso, "Resemblance between gap waveguides and hollow waveguides," IET Microw. Antennas Propag., vol. 7, no. 15, pp. 1221-1227, Dec. 2013.

[13] E. Pucci, A. Zaman, E. Rajo-Iglesias, P.-S. Kildal, and A. Kishk, "Study of Q-factors of ridge and groove gap waveguide resonators," IET Microw., Antennas Propag., vol. 7, no. 11, pp. 900-908, Jun. 2013. 